\title{
Fermentation of Purines and their Effect on the Adenylate Energy Charge and Viability of Starved Peptococcus prévotii
}

\author{
By P. REECE,* D. TOTH† AND E. A. DAWES \\ Department of Biochemistry, University of Hull, Kingston upon Hull, HU6 ${ }_{7} R X$
}

(Received 17 May 1976)

\section{SUMMARY}

The principal products of endogenous metabolism of the obligate anaerobe Peptococcus prévotii were carbon dioxide, ammonia, acetate and butyrate, which are also produced by fermentation of nucleosides, purines and ribose, thus supporting our previous finding that RNA is the only cellular component to undergo substantial degradation under starvation conditions. Minor products were hydrogen, formate and propionate. The stoicheiometries of fermentation of xanthine, adenine, adenosine and ribose were determined. The ability to ferment exogenous nucleosides, purines and ribose declined rapidly on starvation, as did the ability to generate ATP from xanthine, and was paralleled by the loss of viability. However, addition of pulses of xanthine or adenine to organisms in the early stages of starvation sustained their adenylate energy charge and prolonged their viability. Evidence suggests that $P$. prévotii dies when its principal energy source (RNA) is depleted, and a possible explanation is that the transport function of the cytoplasmic membrane decays rapidly under these conditions so that, on transfer to a recovery medium, uptake of nutrients is inadequate to support growth.

\section{INTRODUCTION}

Studies on the survival of the obligately anaerobic micrococcus Peptococcus prévotii in relation to its adenylate energy charge demonstrated that RNA is the only significant substrate for endogenous metabolism and that a rapid fall in the total adenine nucleotide content occurred during the early stages of starvation (Montague \& Dawes, 1974). One possible cause of this decrease could be fermentation of the purine moiety of AMP after dephosphorylation, the adenine nucleotide pool becoming depleted as adenylate kinase continually renews the supply of AMP. We have therefore investigated the fermentation of purines by $P$. prévotii and their possible role in survival during starvation.

Whiteley (1952) found that a related micrococcus, Peptococcus aerogenes, fermented adenine, guanine, hypoxanthine and xanthine and some of these may be fermented by two pathways. The detailed degradation of these purines was not investigated but an unusual finding was the appearance and subsequent dissimilation of certain pyrimidines during the fermentation of purines.

\footnotetext{
* Present address : Humber Laboratory for Fish Technology, Wassand Street, Hull, HU3 4AR.

† Present address: Limnology Sector, Institute of Experimental Biology \& Ecology, Slovak Academy of Sciences, Bratislava, Czechoslovakia.
} 


\section{METHODS}

Growth and harvesting of organism. Peptococcus prévotii ATCCI 4952 was grown at $37{ }^{\circ} \mathrm{C}$ in the complex medium and under the conditions described by Montague \& Dawes ( I974). Higher cell yields were obtained with Oxoid reinforced clostridial medium plus $0.005 \%$ Tween 80 (polyoxyethylene sorbitan mono-oleate) and this medium was used occasionally for the production of larger batches of organisms to prepare cell-free extracts.

Bacteria were harvested, with anaerobic precautions, just before the onset of the stationary phase, washed with previously boiled and cooled $67 \mathrm{~mm}-\mathrm{NaK}$ phosphate buffer $\mathrm{pH} 6.8$, and then resuspended in identical buffer to the required concentration. The density of bacterial cultures and suspensions was measured turbidimetrically at $570 \mathrm{~nm}$ with a Pye Unicam SP60o spectrophotometer using either spent or clarified medium or the appropriate buffer solution as blank. Extinction was proportional to dry weight over the range 0 to 70 $\mu \mathrm{g} \mathrm{ml}^{-1}$, corresponding to $E_{570}$ of 0.24 .

Manometric experiments. Fermentation was measured as gas evolution under an atmosphere of nitrogen, with or without $\mathrm{KOH}$ in the centre well, by conventional Warburg techniques at $37^{\circ} \mathrm{C}$. Vessels contained 5 or $10 \mu \mathrm{mol}$ substrate and $2.3 \mathrm{ml}$ bacterial suspension in $67 \mathrm{~mm}-\mathrm{NaK}$ phosphate buffer $\mathrm{pH} 6 \cdot 8$. Water replaced substrate for controls and for measurement of endogenous fermentation. For total $\mathrm{CO}_{2}$ measurement, $0.2 \mathrm{ml} \mathrm{2.5} \mathrm{M}-\mathrm{H}_{2} \mathrm{SO}_{4}$ was tipped from a second side-arm.

Bacterial extracts. These were prepared under nitrogen by homogenizing $10 \mathrm{ml}$ suspension (about $20 \mathrm{mg}$ dry bacterial wt $\mathrm{ml}^{-1}$ ) in $67 \mathrm{~mm}-\mathrm{NaK}$ phosphate buffer $\mathrm{pH} 6 \cdot 8$, containing I mM-dithiothreitol, with glass beads $(9.2 \mathrm{ml}$ of 100 mesh chromatography beads) in an MSE homogenizer fitted with masticator attachment for a $25 \mathrm{ml}$ Universal bottle (MSE) for $6 \mathrm{~min}$. The bottle was immersed in ice throughout the treatment. The disintegrated suspension was transferred using a nitrogen-filled syringe to a metal-capped centrifuge tube previously flushed with nitrogen. The beads were washed with I to $2 \mathrm{ml}$ of previously boiled and cooled $\mathrm{NaK}$ phosphate buffer $\mathrm{pH} 6.8$, with anaerobic precautions, the washings were transferred by syringe to the centrifuge tube, the cap was tightened to produce an air-tight seal, and the disintegrated suspension was centrifuged twice at $10000 \mathrm{~g}$ for $10 \mathrm{~min}$ at $0{ }^{\circ} \mathrm{C}$ on a Sorvall $\mathrm{RC}_{2} \mathrm{~B}$ centrifuge. The yellow supernatant was transferred by syringe to a Universal bottle previously flushed with nitrogen, and held on ice for immediate use.

Extracts were also prepared by passing bacterial suspensions (Io to $20 \mathrm{ml}$, containing 20 mg dry wt $\mathrm{ml}^{-1}$ in $67 \mathrm{~mm}-\mathrm{NaK}$ phosphate buffer containing I mM-dithiothreitol) through a French pressure cell which was cooled on ice and flushed with nitrogen. The suspension was passed twice through the cell under a pressure of I $57 \mathrm{MPa}$ and collected in a centrifuge tube held on ice and continually flushed with nitrogen. The disintegrated suspension was centrifuged twice at $10000 \mathrm{~g}$ for $\mathrm{i} 0 \mathrm{~min}$ at $0{ }^{\circ} \mathrm{C}$ and the supernatant was kept at $0{ }^{\circ} \mathrm{C}$ for use.

Starvation experiments. Portions of suspension (200 or $400 \mathrm{ml}$, containing 0.5 to $0.6 \mathrm{mg}$ dry wt $\mathrm{ml}^{-1}$ ) prepared from $\mathrm{io} 1 \mathrm{medium}$ were starved anaerobically at $37^{\circ} \mathrm{C}$ as described by Montague \& Dawes (1974).

Determination of viability. The slide culture method of Postgate, Crumpton \& Hunter (I96I) was modified for use with anaerobic bacteria. Metal annuli, sterilized by storage in alcohol and flaming, were dipped in sterile molten agar medium using sterile forceps, placed on alcohol-flamed slides in sterile Petri dishes, and stored at $4{ }^{\circ} \mathrm{C}$. Bacterial suspensions were diluted (usually $\mathrm{I}: \mathrm{I} 00$ of $0.6 \mathrm{mg}$ dry wt $\left.\mathrm{ml}^{-1}\right)$ in molten $\left(40^{\circ} \mathrm{C}\right.$ ) agar medium containing $\left(\%\right.$, w/v): Difco Bacto-peptone, I ; Difco yeast extract, I; $\mathrm{KH}_{2} \mathrm{PO}_{4}$, I ; glucose, 0.5 ; sodium chloride, 0.5; L-cysteine hydrochloride, 0.05; Tween 80, 0.005; Lab M agar 
(London Analytical \& Bacteriological Media, Pendleton, Salford), 2 ; adjusted to $\mathrm{pH} 7 \cdot \mathrm{I}$ with $\mathrm{NaOH}$. A sample of the suspension was transferred to an annulus using a warm pipette and a sterile coverslip was placed over the agar and pressed to the annulus, excluding air bubbles. The Petri dish, containing a drop of sterile water, was then incubated at $37^{\circ} \mathrm{C}$. After $\mathrm{I} 2 \mathrm{~h}$ the agar was examined with a Zeiss photomicroscope, microcolonies being scored as viable units, whereas single cells were scored as dead.

\section{Analyses}

Adenine nucleotides. These were determined by the firefly luminescence method described by Montague \& Dawes (1974) and adenylate energy charges were calculated from the expression $([\mathrm{ATP}]+0.5[\mathrm{ADP}]) /([\mathrm{ATP}]+[\mathrm{ADP}]+[\mathrm{AMP}])$. As previously noted by Montague \& Dawes (1974), release of adenine nucleotides by the organism was negligible up to $12 \mathrm{~h}$ starvation and thereafter quite small. Corrections were applied where necessary by subtracting the amounts of extracellular nucleotides from the total.

Ammonia. The indophenol method of Chaney \& Marbach (I962) was used wherever possible. If interfering compounds were present, the micro-diffusion technique of Conway (1962) was employed.

Protein. The methods of Stickland (195I) and Lowry et al. (195I) were used.

Volatile fatty acids. These were determined by benzylation of the tetra- $n$-butylammonium salts of the fatty acids (Bethge \& Lindström, 1974) and separation of the esters on a gasliquid chromatography column (Io \% diethylene glycol succinate stationary phase on celite I 20-I 30 support) at $120^{\circ} \mathrm{C}$ with an argon flow rate of $43 \mathrm{ml} \mathrm{min}{ }^{-1}$.

$\beta$-Ketothiolase (EC. 2.3. I .9). This was assayed by the method of Senior \& Dawes (1973).

Chemicals and enzymes. Analytical grade reagents were used wherever possible. Substrates and coenzymes were from Sigma and BDH. Myokinase (pig muscle, grade IV) and pyruvate kinase (type II) were from Sigma. Nitrogen gas (from BOC) was bubbled through a solution of sodium dithionite $\left(5 \mathrm{~g}\right.$ in $250 \mathrm{ml} 0.25 \mathrm{M}-\mathrm{K}_{2} \mathrm{HPO}_{4}$ ) to remove traces of oxygen and then through water in a Drechsel bottle.

RESULTS

Fermentation of endogenous substrates. Bacterial suspensions under nitrogen released $\mathrm{CO}_{2}$ and $\mathrm{H}_{2}$ endogenously, in the approximate ratio of $\mathrm{IO}: \mathrm{I}$, at a steady but low rate. Rates varied somewhat with different preparations but the total gas $\left(\mathrm{CO}_{2}\right.$ plus $\left.\mathrm{H}_{2}\right)$ evolution was usually in the range 0.05 to $0.22 \mu \mathrm{mol} \mathrm{h}^{-1}\left(\mathrm{mg}\right.$ dry wt) ${ }^{-1}$. Clearly serine and threonine, the amino acids principally concerned with energy production in $P$. prévotii, could not be wholly responsible since their fermentation yields equimolar amounts of these gases (Bentley \& Dawes, 1974). The other principal products were ammonia, acetate and butyrate with small amounts of formate and propionate (Table I). (Hydrogen was not determined in these experiments but from other analyses was approximately $\mathrm{O} \cdot \mathrm{I}$ of the $\mathrm{CO}_{2}$ output.)

Fermentation of substrates by washed bacterial suspensions. Table 2 shows that, of the substrates tested, the nucleosides adenosine and inosine were fermented at the highest rates, followed by glucose, the rates with ribose and xanthine being significantly lower, although much higher than with other purines and pyrimidines. Thymine and uracil gave variable results - either zero or extremely low rates - whereas adenine and guanine were fermented slowly. For subsequent detailed investigations we selected xanthine, adenine, ribose and adenosine as substrates.

Fermentation by bacterial extracts. We thought that permeability might limit fermentation 


\section{Table I. Products of endogenous metabolism in P. prévotii}

Bacterial suspensions were starved in Warburg vessels at $37^{\circ} \mathrm{C}$ under nitrogen. Products were analysed as described in Methods. Hydrogen was not analysed in these experiments.

Product

$\mathrm{CO}_{2}$
$\mathrm{NH}_{3}$
Formate
Acetate
Propionate
Butyrate
Bacteria per vessel (mg dry wt)
Period of starvation (min)

$\begin{array}{cc}\text { Amount formed }(\mu \mathrm{mol}) \\ 23 \cdot 0 & 20 \cdot 0 \\ 10 \cdot 2 & 8 \cdot 0 \\ 3 \cdot 1 & * \\ 12 \cdot 0 & 9 \cdot 1 \\ 1 \cdot 2 & 0 \cdot 2 \\ 17 \cdot 6 & 9 \cdot 8 \\ 34 \cdot 6 & 18 \cdot 4 \\ 1300 & 1285\end{array}$

* Formate was not detected by the column used in this experiment.

Table 2. Fermentation of substrates by washed suspensions of $P$. prévotii

Specific activities are expressed as nmol total gas evolved $h^{-1}(m g \text { dry } w t)^{-1}$. Values have been corrected for the endogenous activity $\left[57 \mathrm{nmol}\right.$ total gas evolved $\left.\mathrm{h}^{-1}(\mathrm{mg} \mathrm{dry} \mathrm{wt})^{-1}\right]$.

Substrate added

Xanthine

Adenine

Guanine

Cytosine

Uracil

Thymine

Uric acid

Hypoxanthine
Specific activity Substrate added

I83 Thymidine

59 Cytidine

23 Inosine 4I3

O* Guanosine 78

o* 4-Amino-5-imidazole carboxamide 20

53 Ribose $18 \mathrm{I}$

I23 Glucose 353

* Result variable but either zero or very low value.

of some substrates, but cell extracts prepared by a variety of different techniques, including homogenization with glass beads, French pressure cell and sonication, were all inactive and, over a long period of investigation using organisms grown on different media, we failed to secure fermentative activity.

Stoicheiometry of fermentations. Analyses of fermentation products gave the following stoicheiometries:

$$
\begin{aligned}
& \text { Xanthine } \longrightarrow 2 \cdot 9 \mathrm{ICO}_{2}+4.03 \mathrm{NH}_{3}+\mathrm{I} \cdot 06 \text { acetate } \\
& \text { Adenine } \longrightarrow 2.74 \mathrm{CO}_{2}+5.0 \mathrm{NH}_{3}+\mathrm{I} \cdot \mathrm{I} 2 \text { acetate } \\
& \text { Adenosine } \longrightarrow 4.24 \mathrm{CO}_{2}+4.95 \mathrm{NH}_{3}+\mathrm{I} \cdot 0 \text { acetate }+\mathrm{I} \cdot 09 \text { butyrate } \\
& \text { Ribose } \longrightarrow \text { I.06 } \mathrm{CO}_{2}+0.96 \mathrm{NH}_{3}+0 . \mathrm{I} \text { I acetate }+0.98 \text { butyrate. }
\end{aligned}
$$

Unexpectedly, ribose stimulated endogenous ammonia release and the carbon balance was accounted for by $\mathrm{CO}_{2}$ and butyrate. Butyrate formation could be explained by the condensation of two acetyl-CoA molecules catalysed by $\beta$-ketothiolase and the subsequent reduction of acetoacetyl-CoA. $\beta$-Ketothiolase was present in extracts of $P$. prévotii.

The principal products of the fermentation of these purines, adenosine and ribose are similar to those released during endogenous metabolism (Table I) although clearly there is an additional endogenous source of $\mathrm{CO}_{2}$.

Effect of starvation on the ability to ferment purines, nucleosides and ribose. The fermentative capacity of starved suspensions towards different substrates varied during the early 
Table 3. Effect of starvation on the ability of $P$. prévotii to ferment adenine, xanthine, adenosine and ribose

Bacteria $\left(0.5 \mathrm{mg}\right.$ dry wt $\left.\mathrm{ml}^{-1}\right)$ in $400 \mathrm{ml} 67 \mathrm{~mm}$-phosphate buffer pH 6.8 were starved at $37{ }^{\circ} \mathrm{C}$. Samples were withdrawn at intervals and their fermentative activities were measured in Warburg respirometers with substrates present at $4 \mathrm{~mm}$. The first values recorded for each substrate were all obtained with the same batch of organisms. The other values were obtained with different batches. Fermentative activities are expressed as nmol total gas evolved $\mathrm{h}^{-1}(\mathrm{mg} \text { dry wt })^{-1}$ and have been corrected for endogenous gas release.

\begin{tabular}{|c|c|c|c|c|c|c|c|c|c|c|c|c|}
\hline \multirow[b]{2}{*}{ Substrate } & \multirow{2}{*}{$\begin{array}{l}\text { Period of } \\
\text { starvation (h) }\end{array}$} & \multicolumn{11}{|c|}{ Fermentative activity } \\
\hline & & 2.5 & $3 \cdot 5$ & 4 & 6 & 7 & 8 & II & $12 \cdot 5$ & 13 & 15 & 26 \\
\hline None & & & 30 & & & 18 & & & & & & II \\
\hline \multirow[t]{2}{*}{ Adenine } & & & 80 & & & 66 & & & & & & 0 \\
\hline & & & 40 & & 24 & & IO & & 8 & & 8 & 0 \\
\hline \multirow[t]{2}{*}{ Xanthine } & & & 200 & & & 158 & & & & & & I \\
\hline & & 245 & & 145 & & & 130 & 112 & & & & 8 \\
\hline \multirow[t]{2}{*}{ Adenosine } & & & 510 & & & 500 & & & & & & 33 \\
\hline & & 300 & & & I 30 & & II 2 & & 12 & IO & & 10 \\
\hline \multirow[t]{2}{*}{ Ribose } & & & 800 & & & 500 & & & & & & 4 \\
\hline & & & 398 & & 168 & & 126 & & 55 & & & \\
\hline
\end{tabular}

Table 4. Intracellular concentrations of adenine nucleotides in starving

$P$. prévotii supplemented or unsupplemented with xanthine

Two suspensions (each of $200 \mathrm{ml} ; 0.6 \mathrm{mg}$ dry $\mathrm{wt} \mathrm{ml}^{-1}$ ) were starved at $37^{\circ} \mathrm{C}$. To one, I mM-xanthine was added immediately after withdrawing the $2 \mathrm{~h}$ sample. Samples $(3 \mathrm{ml})$ were taken at intervals for determination of adenine nucleotides. Results are expressed as nmol (mg dry wt $)^{-1}$.

\begin{tabular}{|c|c|c|c|c|c|c|c|c|c|c|}
\hline \multirow{2}{*}{$\begin{array}{l}\text { Time from } \\
\text { start of } \\
\text { harvesting } \\
\text { (h) }\end{array}$} & \multicolumn{5}{|c|}{ Supplemented } & \multicolumn{5}{|c|}{ Unsupplemented } \\
\hline & ATP & ADP & AMP & Total & $\begin{array}{l}\text { Adenylate } \\
\text { energy } \\
\text { charge }\end{array}$ & ATP & ADP & AMP & Total & $\begin{array}{c}\text { Adenylate } \\
\text { energy } \\
\text { charge }\end{array}$ \\
\hline 0 & 0.43 & 0.55 & 0.04 & 1.02 & 0.69 & 0.43 & 0.55 & 0.04 & 1.02 & 0.69 \\
\hline 2 & $0 \cdot 26$ & 0.64 & 0.04 & 0.94 & 0.62 & 0.26 & 0.64 & 0.04 & 0.94 & 0.62 \\
\hline \multicolumn{11}{|c|}{ Xanthine added } \\
\hline $2 \cdot 5$ & 0.48 & 0.38 & 0.08 & 0.94 & $0.7 \mathrm{I}$ & 0.26 & 0.38 & 0.03 & 0.67 & 0.67 \\
\hline 4 & 0.64 & 0.45 & $0 \cdot 13$ & $1 \cdot 22$ & $0.7 \mathrm{I}$ & 0.26 & 0.20 & 0.08 & 0.54 & 0.66 \\
\hline 5 & 0.66 & 0.42 & 0.22 & $1 \cdot 30$ & 0.67 & 0.25 & 0.10 & $0.2 I$ & 0.56 & 0.54 \\
\hline $6 \cdot 5$ & 0.44 & $0.2 \mathrm{I}$ & 0.20 & 0.85 & 0.64 & 0.20 & 0.08 & 0.29 & 0.57 & 0.42 \\
\hline $8 \cdot 5$ & 0.38 & 0.20 & 0.20 & 0.78 & 0.61 & 0.17 & 0.07 & 0.27 & 0.51 & 0.40 \\
\hline 10.5 & 0.22 & 0.20 & 0.20 & 0.62 & $0.5 \mathrm{I}$ & 0.16 & 0.06 & 0.21 & 0.42 & 0.44 \\
\hline I 5 & 0.15 & 0.20 & 0.20 & 0.55 & 0.45 & 0.12 & 0.06 & 0.23 & 0.41 & 0.37 \\
\hline 24 & 0.08 & 0.20 & O.I I & 0.39 & 0.46 & 0.07 & 0.05 & 0.13 & 0.25 & 0.38 \\
\hline
\end{tabular}

stages of starvation. Activity towards all substrates declined and after $26 \mathrm{~h}$ the organisms were essentially inactive (Table 3). Similar observations were made with hypoxanthine, guanine and uracil fermentation. Different batches of organisms displayed variations in their rates of fermentation when freshly harvested.

Effect of starvation on the ATP content of $P$. prévotii and on its ability to generate ATP from xanthine. The ATP content of $P$. prévotii fell gradually during starvation. However, in the early stages of starvation the organism could generate ATP rapidly from added pulses of $2 \mathrm{~mm}$-xanthine although this ability declined fairly quickly and was lost completely after starvation for $\mathrm{I} 5 \mathrm{~h}$ (Fig. I). 


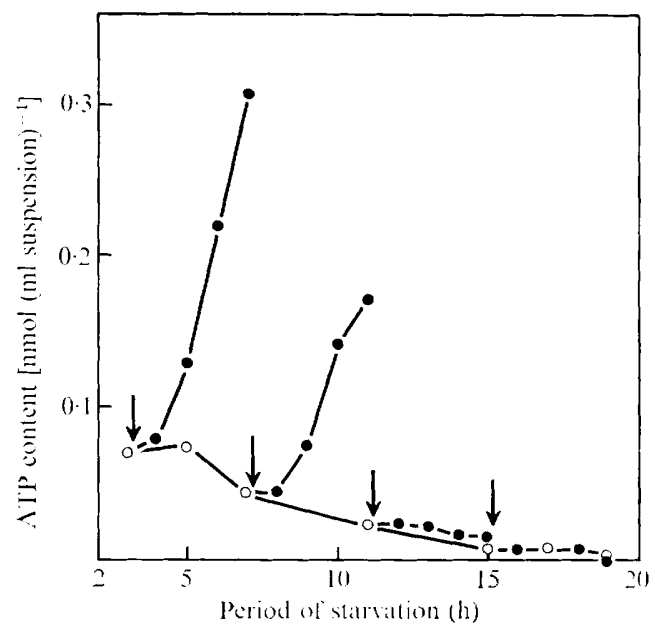

Fig. I. Effect of starvation on the ATP content of $P$. prévotii and on its ability to generate ATP from pulses of xanthine. A bacterial suspension $\left(0.62 \mathrm{mg} \mathrm{ml}^{-1}\right)$ in $400 \mathrm{ml} 67 \mathrm{~mm}$-phosphate buffer pH 6.8 was divided into two equal portions and starved at $37^{\circ} \mathrm{C}$ under nitrogen. One portion served as the control and the other was sampled at the times indicated by the arrows, pulsed with 2 mM-xanthine (final concn) and ATP formation was measured. Xanthine added; $\bigcirc$, control.



Fig. 2. Effect of single pulses of $(a)$ xanthine or $(b)$ adenine on the adenylate energy charge and viability of starving $P$. prévotii. In each experiment $400 \mathrm{ml}$ bacterial suspension in $67 \mathrm{~mm}$-phosphate buffer pH 6.8 was divided into two equal portions and starved at $37^{\circ} \mathrm{C}$ under nitrogen. One portion served as the control and the other was pulsed with I mM-purine (final concn) at the time indicated by the arrow. O, $\mathrm{E}$, Purine added; $O, \square$, control. Bacterial densities were $(a) 0.50$ and $(b) 0.44 \mathrm{mg}$ dry wt $\mathrm{ml}^{-1}$. 


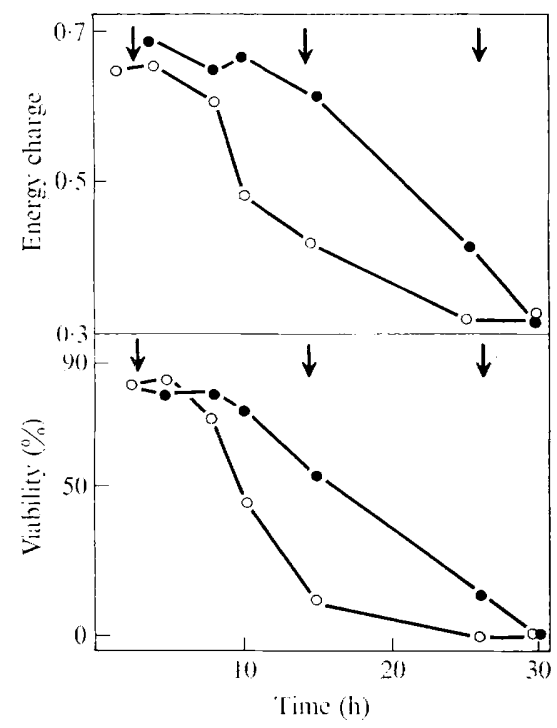

Fig. 3. Effect of sequential pulses of xanthine on the adenylate energy charge and viability of starving $P$. prévotii. A bacterial suspension $\left(0.72 \mathrm{mg} \mathrm{ml}^{-1}\right)$ in $400 \mathrm{ml} 67 \mathrm{~mm}$-phosphate buffer $\mathrm{pH} 6.8$ was divided into two equal portions and starved at $37^{\circ} \mathrm{C}$ under nitrogen. One portion served as the control and the other was pulsed with I mM-xanthine (final concn) at the times indicated by the arrows. Xanthine added; $O$, control.

Effect of xanthine and adenine on the adenylate energy charge and viability of starved $P$. prévotii. The addition of xanthine in the early stages of starvation maintained the adenylate energy charge at approx. 0.64 or above for about $6.5 \mathrm{~h}$ while the corresponding value for an unsupplemented control dropped to 0.42 in the same period (Table 4). As well as sustaining the energy charge, the addition of xanthine improved survival (Fig. $2 a$ ); in this case, the energy charge was maintained at 0.65 to 0.7 for I I h. Adenine had a similar effect on energy charge and viability (Fig. $2 b$ ), but I mM-uracil had no effect on the intracellular adenylate concentrations during starvation, in keeping with its fermentative behaviour recorded in Table 2.

We attempted to prolong viability by adding pulses of xanthine at intervals during starvation (Fig. 3) but survival was not greatly enhanced. The timing of the pulses was evidently critical. Continuous addition of the substrate would probably be better but the solubility of xanthine is low and changes in bacterial density would result from dilution on such addition thereby introducing a new parameter, so we abandoned this approach.

\section{DISCUSSION}

Serine and threonine serve as energy sources for $P$. prévotii during starvation (Montague \& Dawes, 1974; Bentley \& Dawes, 1974); our results show that adenine and xanthine can also fulfil this role. The rapid fall in total adenine nucleotide content observed by Montague $\&$ Dawes (I974) in the early stages of starvation could thus be accounted for by dephosphorylation of AMP followed by fermentation of the purine moiety. Likewise, the marked fall in RNA content which occurs during starvation would furnish purines and ribose for endogenous fermentation, give the products detected, and provide the major substrates for endogenous energy production. The addition of either adenine or xanthine to a starving 
suspension prolonged the period for which the adenylate energy charge could be sustained at a high value, and, concomitantly, prolonged the viability. Correlation of energy charge with viability is thus again confirmed with this organism.

The observed stoicheiometry of xanthine fermentation accords with that reported for anaerobic clostridia (Rabinowitz \& Barker, I956; Rabinowitz, I956) suggesting that 4-amino-5-imidazole carboxylic acid might be an intermediate. The low rate of fermentation of this compound (Table 2) could be due to poor permeation but our inability to secure active cell-free extracts precluded further investigation of the fermentation pathway. The pattern of fermentation with intact cells reveals, however, that $P$. prévotii differs from the related $P$. aerogenes (Whiteley, 1952) in its activity towards purines and pyrimidines, as well as towards amino acids (Bentley \& Dawes, 1974).

The rapid loss of fermentative activity of $P$. prévotii towards purines and nucleosides essentially parallels the loss of viability of the organism during starvation; a similar situation was noted with serine fermentation (Montague \& Dawes, 1974) but we were unable to correlate death of the organism with the loss of any of the intracellular enzymes concerned with energy generation from this amino acid or threonine (Bentley \& Dawes, 1974). Direct measurements have recently revealed, however, that the ability of $P$. prévotii to transport serine is lost during starvation (P. Reece \& E. A. Dawes, unpublished observations). The cytoplasmic membrane is thus implicated in the cellular changes that occur during starvation.

The greatest obstacle encountered in the present work was our inability to secure cellfree extracts which would ferment purines; treatments which affected the integrity of the cytoplasmic membrane simultaneously resulted in loss of fermentative ability.

The concept of maintenance energy in relation to the survival of starving organisms leads to the prediction that if energy could be supplied at a rate commensurate with their maintenance requirements they should survive indefinitely. Continuous feeding of an energy source (glucose) at an appropriate rate during starvation did extend the survival period of Streptococcus lactis and corresponded to a maintenance requirement of 0.045 to $0.090 \mathrm{~g}$ glucose (g dry wt) ${ }^{-1} \mathrm{~h}^{-1}$ (Thomas \& Batt, 1969 ). The technique of continuous feeding could not, however, be applied satisfactorily with purines on account of their low solubility, although this approach should be feasible with serine and adenosine.

Montague \& Dawes (1974) showed that RNA was the only endogenous component to undergo significant depletion during starvation. Since the loss of viability of $P$. prévotii can be delayed by supplying the bacteria with purines as an energy source, our previous conclusion that death of this organism is a result of the depletion of its energy reserves is further supported. The critical consequences of energy depletion on cellular function in relation to survival await definition, although, as discussed, there is some evidence to suggest that maintenance of the functional integrity of the cytoplasmic membrane is involved. As $P$. prévotii is an obligate anaerobe the membrane would be expected to be energized for transport by ATP directly, via an ATPase ; preliminary experiments with dicyclohexylcarbodiimide and carbonylcyanide $m$-chlorophenylhydrazone indicate that this is so. Thus ATP depletion, with consequent loss of transport activity, might effectively prevent the uptake of nutrients at a rate sufficient to support growth when such starved cells are transferred to a recovery medium.

We acknowledge with gratitude the award of a World Health Organization Fellowship to D.T. 


\section{REFERENCES}

Bentley, C. M. \& Dawes, E. A. (1974). The energy-yielding reactions of Peptococcus prévotii, their behaviour on starvation and the role and regulation of threonine dehydratase. Archives of Microbiology roo, 363-387.

BethGe, P. O. \& Lindström, K. (1974). Determination of organic acids of low relative molecular mass $\left(\mathrm{C}_{1}\right.$ to $\left.\mathrm{C}_{4}\right)$ in dilute aqueous solution. Analyst $99, \mathrm{I} 37-\mathrm{I} 42$.

Chaney, A. L. \& Marbach, E. P. (1962). Modified reagents for determination of urea and ammonia. Clinical Chemistry 8, I30-132.

Conway, E. J. (1962). Microdiffusion Analysis and Volumetric Error. London: Crosby Lockwood.

Lowry, O. H., Rosebrough, N. J., Farr, A. L. \& Randall, R. J. (I95I). Protein measurement with the Folin phenol reagent. Journal of Biological Chemistry 193, 265-275.

Montague, M. D. \& Dawes, E. A. (I974). The survival of Peptococcus prévotii in relation to the adenylate energy charge. Journal of General Microbiology 80, 29I-299.

Postgate, J. R., Crumpton, J. E. \& Hunter, J. R. (1961). The measurement of bacterial viabilities by slide culture. Journal of General Microbiology 24, 15-24.

Rabinowitz, J. C. (1956). Purine fermentation by Clostridium cylindrosporum. III. 4-Amino-5-imidazolecarboxylic acid and 4-aminoimidazole. Journal of Biological Chemistry 218, 175-187.

Rabinowitz, J. C. \& Barker, H. A. (1956). Purine fermentation by Clostridium cylindrosporum. II. Purine transformations. Journal of Biological Chemistry 218, 16I-174.

Senior, P. J. \& Dawes, E. A. (I973). The regulation of poly- $\beta$-hydroxybutyrate metabolism in Azotobacter beijerinckii. Biochemical Journal 134, 225-238.

Stickland, L. H. (195I). The determination of small quantities of bacteria by means of the biuret reaction. Journal of General Microbiology 5, 698-703.

Thомаs, T. D. \& Batт, R. D. (1969). Metabolism of exogenous arginine and glucose by starved Streptococcus lactis in relation to survival. Journal of General Microbiology 58, 371-380.

Whiteley, H. R. (1952). The fermentation of purines by Micrococcus aerogenes. Journal of Bacteriology $\mathbf{6}_{3}$, I 63-175. 